See discussions, stats, and author profiles for this publication at: https://www.researchgate.net/publication/273218579

\title{
Synthesis of Methoxyisopropyl (MIP)-Protected ( R )-Mandelonitrile and Derivatives in a Flow Reactor
}

Article in Journal of Flow Chemistry · December 2012

DOI: 10.1556/JFC-D-12-00008

\section{CITATIONS}

5 authors, including:

Mariëlle Langereis - Delville

Radboud University

8 PUBLICATIONS 235 CITATIONS

SEE PROFILE

Jan C M van Hest

Radboud University

386 PUBLICATIONS 15,241 CITATIONS

SEE PROFILE

Some of the authors of this publication are also working on these related projects:

Liposomes View project

Project

Poly(2-oxazoline)s View project

\section{READS}

80

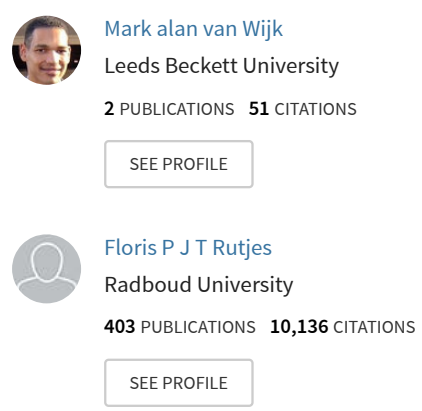




\title{
Synthesis of Methoxyisopropyl (MIP)-Protected $(R)$-Mandelonitrile and Derivatives in a Flow Reactor
}

\author{
Mariëlle M.E. Delville, Jasper J.F. van Gool, Ivo M. van Wijk, \\ Jan C.M. van Hest and Floris P.J.T. Rutjes*
}

Radboud University Nijmegen, Institute for Molecules and Materials, Heyendaalseweg 135, 6525 AJ, Nijmegen, the Netherlands

\begin{abstract}
Cyanohydrins are synthetically versatile chiral building blocks in organic synthesis. They can be conveniently synthesized in enantiomerically pure form via chemoenzymatic hydrogen cyanide addition onto the corresponding aldehyde using hydroxynitrile lyase. Recently, we reported that such transformations can be efficiently carried out in a continuous flow manner using microreactors. Since racemization of enantiopure cyanohydrins occurs readily under slightly basic conditions, they should be protected before the follow-up reactions, preferably under acidic conditions. In this contribution, we demonstrate that the methoxyisopropyl protection of mandelonitrile can be conveniently optimized in an automated microscale continuous flow system and subsequently scaled up under the same conditions by applying a larger flow reactor.
\end{abstract}

Keywords: mandelonitrile, flow chemistry, reaction optimization, microreactor, MIP-protection

\section{Introduction}

Cyanohydrins are found in plants, bacteria, fungi, and many insects as part of their defense mechanism, which involves enzymatic release of highly toxic hydrogen cyanide [1]. In addition, cyanohydrins serve as a source of nitrogen for the biosynthesis of amino acids [2]. The natural occurrence of cyanohydrins and their versatile applications render them an interesting compound class for industry. In 1903, Lapworth already reported on the synthetic racemic hydrocyanation of aldehydes [3]. Five years later, Rosenthaler published an enantioselective cyanohydrin synthesis using an enzyme-catalyzed addition reaction [4]. Ever since, the synthesis of (non-)racemic cyanohydrins gained interest resulting in a wide range of synthetic methods $[1 \mathrm{~b}, 5]$. Cyanohydrins contain synthetically strategic functional groups, making them excellent building blocks for more complex structures, and hence, they found widespread application in both academic and more applied research [5].

Recently, Koch et al. reported a chemoenzymatic synthesis of enantiopure cyanohydrins in a continuous flow system [6]. The synthesis was performed using a crude cell lysate containing a hydroxynitrile lyase (HNL). Making use of a biphasic system in a microreactor with suitably designed microchannels, they were able to efficiently form cyanohydrins in high enantiomeric excess (ee) in an uncontrolled slug flow. Since racemization of enantiopure cyanohydrins occurs readily under slightly basic conditions, they should be suitably protected directly after formation. For this reason, and also due to the fact that the stability of cyanohydrins may vary with the nature of the substituents, potentially leading to decomposition and release of toxic hydrogen cyanide, a flow approach that is directly coupled to the continuous formation of cyanohydrins is intrinsically safer and, hence, advantageous as compared to the corresponding batch process.

In this article, we describe the development of a generally applicable microreactor-based continuous flow method for the protection of cyanohydrins. In literature, a wide range of cyanohydrin protecting groups is known. Not only silyl protecting groups have been applied, but also acetyl, tetrahydropyranyl (THP) [7], and methoxyisopropyl (MIP) groups. Based on previous experience in our group [5g, 8], we chose to investigate the MIP protection for the optimization in the microreactor.

\footnotetext{
* Author for correspondence: f.rutjes@science.ru.n
}

\section{Results and Discussion}

2.1. Synthesis. Mandelonitrile (1) was chosen as a model substrate for the MIP protection of cyanohydrins (Scheme 1). 2- Methoxypropene (2) was used as the reagent of choice because it is cheap and has a boiling point of $55{ }^{\circ} \mathrm{C}$, so that excess reagent can be readily removed while evaporating the solvent methyl tert-butyl ether (MTBE). The reaction should be carried out using a catalytic amount of acid. Initial experiments were performed by adding phosphoryl chloride $\left(\mathrm{POCl}_{3}\right)$, which leads to in situ formation of $\mathrm{HCl}$ [9]. Unfortunately, the results were not reproducible, which is probably due to varying amounts of water present in the different solvents and hence, different concentrations of acid. Next, a regular strong acid, camphorsulfonic acid (CSA), was used. Test experiments showed no difference in yield when using a catalytic amount of dry CSA or the corresponding hydrate. When CSA was used to catalyze the batch reactions, thin-layer chromatography showed complete consumption of starting material, many spots, and only a small amount of product formation. However, in the continuous flow process, there are no mass and heat transport limitations, and reactions can be accurately controlled, thereby avoiding side products [10].

To ensure well-defined reaction times in the continuous flow system a robust quenching method had to be established. Adding $1.1 \mathrm{Eq}$ of di-isopropylethylamine (DIPEA) with respect to mandelonitrile (1) to the reaction mixture caused the reaction to stop instantaneously. Off-line analysis of the reaction mixture was performed using gas chromatography (GC)-mass spectrometry (MS) or chiral high-performance liquid chromatography (HPLC). For proper analysis, three internal standards (one for each solution) and one external standard were added via the flow marker method previously described by Nieuwland et al. [11]. The standards chosen were ortho-xylene, nitrobenzene, 4-chloro-3-nitrotoluene, and 2,6-dichlorotoluene.

2.2. Flow Chemistry. Figure 1 shows a schematic representation of the setup that was used for the flow experiments. All parts within the dotted line are integrated in a single glass microreactor with an internal volume of $92 \mu \mathrm{L}$, a channel width of $600 \mu \mathrm{m}$, a channel depth of $500 \mu \mathrm{m}$, and an effective channel length of $360 \mathrm{~mm}$. The channel layout contains two mixing units $\mathrm{M}$, being of the folding flow type [12]. All reagents were put in different syringes circumventing undesired (side)-product formation before the start of the reaction. Mandelonitrile (1) and 
Scheme 1. Synthesis of MIP-protected mandelonitrile (3), starting from mandelonitrile (1) and 2-methoxypropene (2)

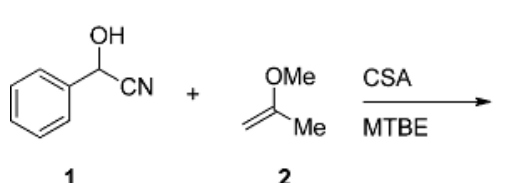

1<smiles>CC(C)(O[Na])Oc1ccccc1</smiles>

3<smiles>C[C@@H]1CC(=O)C[C@@](C)(OS(=O)(=O)O)C1</smiles>

camphorsulfonic acid (CSA) 2-methoxypropene (2) were combined via a T-junction before entering the glass chip using $10 \mathrm{~cm}$ of tubing (inside diameter $254 \mu \mathrm{m})$ to connect the T-junction and the chip.

Before optimizing the synthesis of MIP-protected mandelonitrile (3), the critical process parameters were determined. A basic set of reaction parameters was chosen - reaction time, equivalent of acid, equivalent of 2-methoxypropene (2), and temperature - of which one parameter was changed at a time. The results of the univariate screening are depicted in Figure 2. Reaction time has, as expected, a large influence on the GC yield of MIP-protected mandelonitrile (3) (Figure 2a). At higher acid concentrations a side reaction, possibly 2-methoxypropene polymerization, becomes increasingly important consuming reagent $\mathbf{2}$ and therefore decreasing the yield of the desired product (Figure 2b). As a consequence, the amount of 2-methoxypropene (2) should be sufficiently high $(>10 \mathrm{Eq})$ as shown in Figure 2c. Figure $2 \mathrm{~d}$ shows that raising the reaction temperature led to increase in GC yield until the product started to degrade around $60{ }^{\circ} \mathrm{C}$.

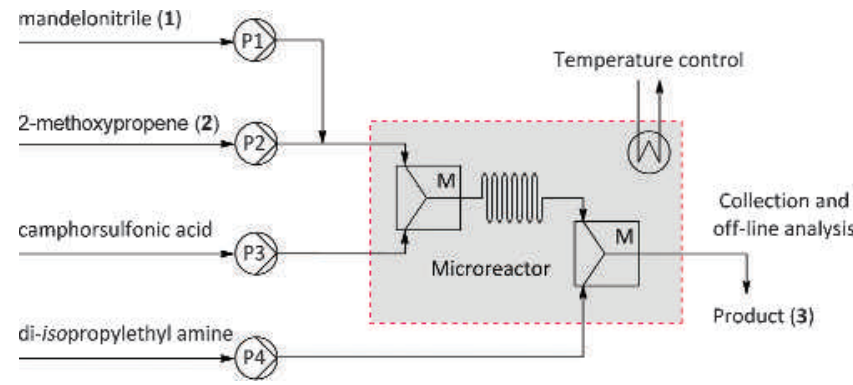

Figure 1. A schematic overview of the microreactor setup
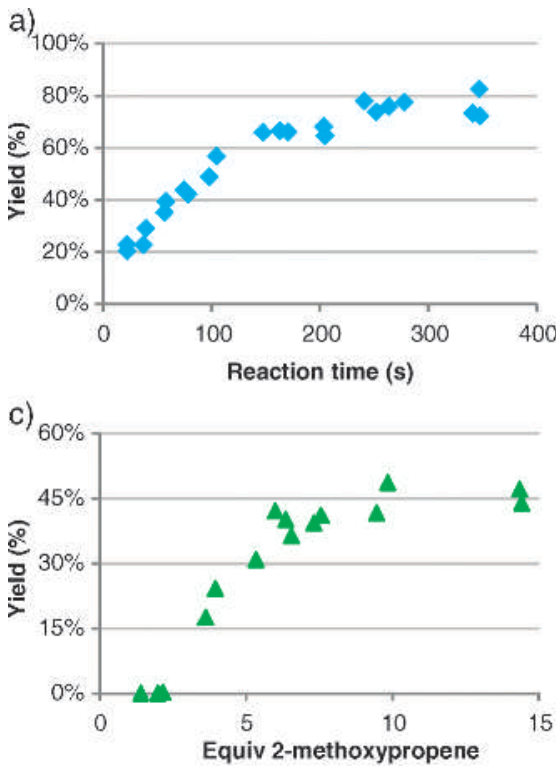

2.3. Multivariate Optimization. Based on the univariate screening, all four process parameters were considered critical for the reaction. The range in which each parameter was screened is shown in Table 1. A multivariate optimization was set up using a Design of Experiment approach. A D-optimal algorithm was used to obtain the experimental design with MATLAB (MathWorks, R2007a). This led to a set of 72 data points, of which the corresponding experiments were performed in random order. The resulting GC yields were normalized and fitted to a third order polynomial model. Recently, in-house developed FlowFit software [13] was used to calculate the best possible model fit providing a set of optimal values for the reaction parameters. The results are visualized in the twodimensional contour plots shown in Figure 3.

Figure 3 a shows already an $80-90 \%$ yield of the reaction at around $40{ }^{\circ} \mathrm{C}$ and $3 \mathrm{Eq}$ of 2 -methoxypropene. However, decreasing or increasing the temperature has a negative effect on the reaction. In the first case, the reaction is simply not completed. In the second case, at higher temperatures, the rate of polymerization of 2-methoxypropene (2) increased. Raising the amount of 2-methoxypropene (2) initially leads to a higher rate of polymerization. At sufficiently high 2-methoxypropene (2) concentration $(>10 \mathrm{Eq})$, however, product formation is favored over the side reaction. Initially one would think that

Table 1. Overview of the critical reaction parameters screened in a multivariate optimization

\begin{tabular}{lc}
\hline Parameter & Range \\
\hline Reaction time & $75-250 \mathrm{~s}$ \\
Equiv CSA & $0.01-0.07$ \\
Equiv methoxypropene & $4-10$ \\
Temperature & $5-60{ }^{\circ} \mathrm{C}$ \\
\hline
\end{tabular}

b)
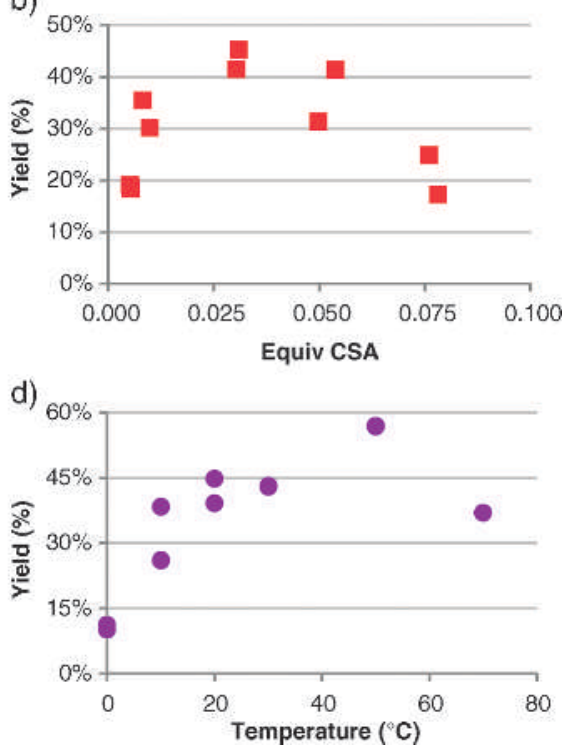

Figure 2. Univariate screening of the synthesis of MIP-protected mandelonitrile (3). Standard conditions: $60 \mathrm{~s}$ of reaction time, 0.03 Eq of CSA, 7 Eq of methoxypropene, $20^{\circ} \mathrm{C}$ 
a)

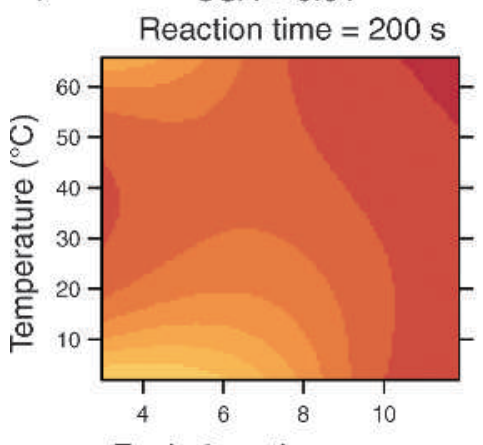

Equiv 2-methoxypropene

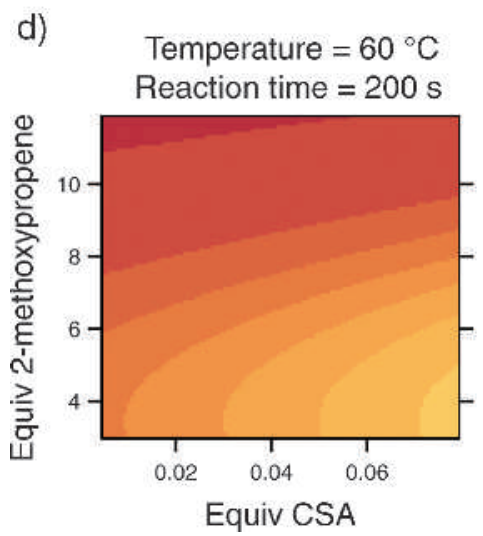

b)

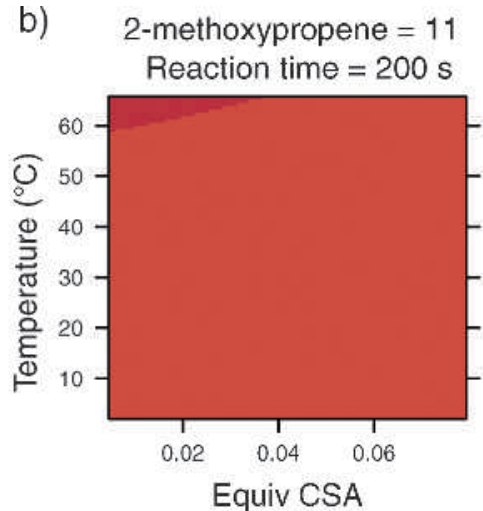

e)

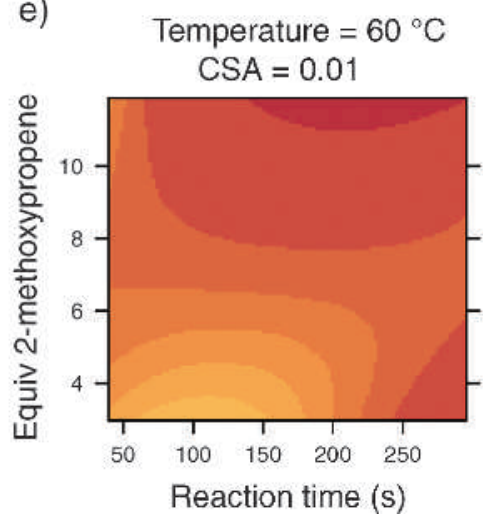

c)
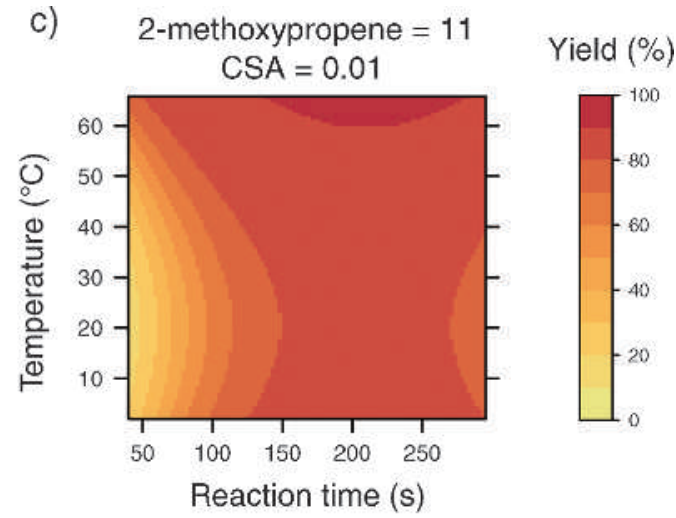

f)

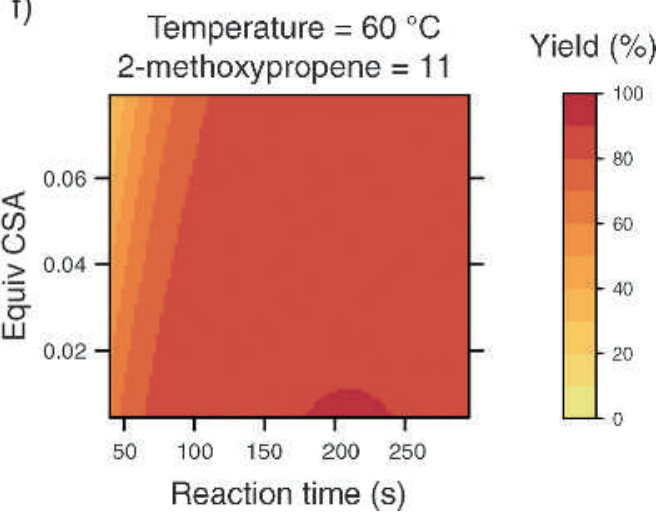

Figure 3. Contour plots provided by the FlowFit program based on the multivariate optimization

when having more than $10 \mathrm{Eq}$ of 2-methoxypropene (2) present, increasing temperatures will not benefit the desired reaction based on the reasons stated above. However, the analysis of the DoE results shows that high temperatures do improve product formation above the critical level of 2-methoxypropene (2) concentration. Figures $3 \mathrm{~d}$ and $3 \mathrm{e}$ underline that higher amounts of 2-methoxypropene (2) are required. The amount of CSA, as mentioned earlier for the univariate experiments, has an optimum around $0.01 \mathrm{Eq}$ (Figures $3 \mathrm{~d}$ and $3 \mathrm{f}$ ). Reaction time seems to have a narrow optimum around $200 \mathrm{~s}$, after which product decomposition is observed (Figures $3 \mathrm{c}, 3 \mathrm{e}$, and $3 \mathrm{f}$ ). Figure $3 \mathrm{~b}$ shows only minor influences of temperature vs. amount of CSA on the reaction although in combination with the parameters reaction time and 2-methoxypropene (2) concentration, they are critical for the reaction. Based on these observations, the optimal reaction conditions were determined as follows: reaction time of $200 \mathrm{~s}$, temperature at $60{ }^{\circ} \mathrm{C}$ using $11 \mathrm{Eq}$ of 2-methoxypropene (2), and $1 \mathrm{~mol} \%$ of CSA.

2.4. Multigram Scale and Enantiopurity. Based on the results and data interpretation of the small scale multivariate optimization experiments, a gram scale experiment was performed using a Uniqsis FlowSyn reactor. For the synthesis of MIP-protected mandelonitrile (3), the optimal conditions were directly implemented. A 20-mL stainless steel coil required a total flow rate of $6 \mathrm{~mL} / \mathrm{min}$ at $60{ }^{\circ} \mathrm{C}$. The crude product was collected in $30 \mathrm{~mL}$ of quenching solution for $14 \mathrm{~min}$. After washing, $1.19 \mathrm{~g}$ of MIP-protected mandelonitrile (3, $83 \%$ isolated yield) was obtained. Thus, by using this set-up, the reaction was successfully scaled up 200 times.

The absolute configuration was maintained during the reaction when starting from $(R)$-mandelonitrile [14]. Chiral HPLC analysis of the formed product showed complete retention of configuration on the chiral center of MIP-protected $(R)$ mandelonitrile.

2.5. Extension of Substrate Scope. To gain further insight in the scope and limitations of this approach, a series of regular alcohols and some additional cyanohydrins were subjected to these optimized flow conditions (Table 2). Remarkably, allyl alcohol (4) did not give any product formation according to the nuclear magnetic resonance (NMR) analysis. In contrast, menthol (6) did react at $20{ }^{\circ} \mathrm{C}$ to produce a mixture of anticipated product 7 and the corresponding elimination product 8 in a 1:1.6 ratio. Raising the temperature to $50{ }^{\circ} \mathrm{C}$ resulted in the exclusive formation of elimination product 8. After workup, enol ether 8 was obtained in $64 \%$ isolated yield.

It is hypothesized that the more electron-rich alcohol (compared to the cyanohydrin alcohol) facilitates the elimination process as depicted in Scheme 2. In addition, the less electron-rich alcohol function of phenol (9) was under the optimized conditions cleanly converted into the corresponding MIP-product, along with starting material (isolated product yield $23 \%$ ). The aliphatic substrate acetone cyanohydrin (11) did not give any product formation according to NMR analysis, probably due to the sterically hindered nature of the alcohol.

To validate the newly established flow conditions on a somewhat larger scale, three mandelonitrile derivatives were tested under the same conditions. MIP-protected $(R)-4-$ chloromandelonitrile (13), $(R)$-4-methylmandelonitrile (15), and $(R)-4$-methoxymandelonitrile (17) were all isolated in reasonable yields, albeit that the yields determined by ${ }^{1} \mathrm{H}$ NMR were clearly higher (Table 2).

Scheme 2. Formation of elimination product 8

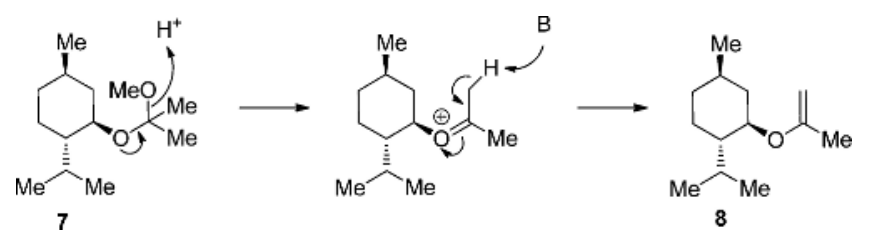


Table 2. Extension of substrate scope

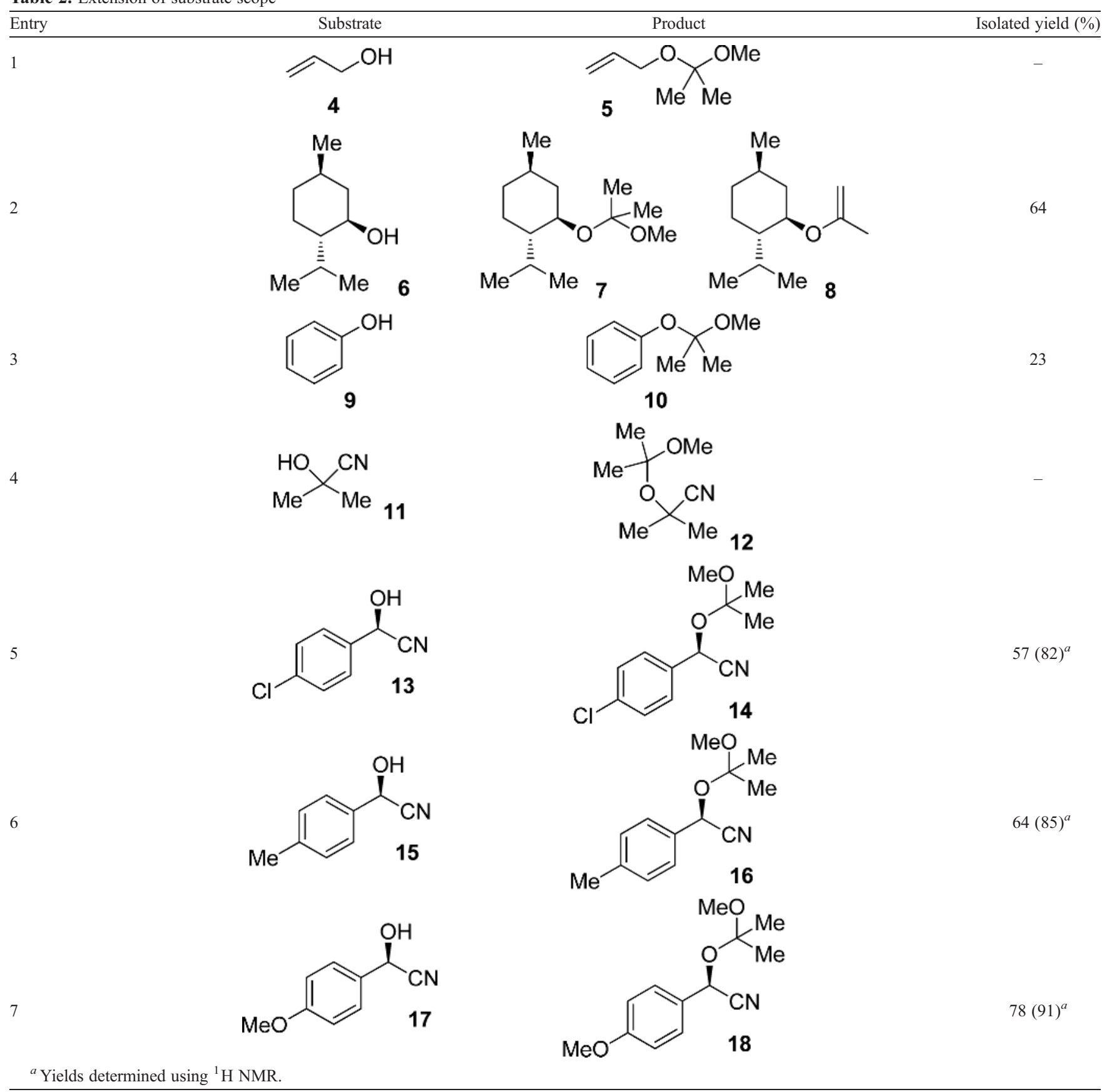

\section{Conclusion}

Protection of racemization prone cyanohydrins can be readily executed in a continuous flow microreactor system. A model substrate, mandelonitrile, was protected using an MIP-protecting group at small scale. During the automated continuous flow optimization, the following set of parameters were investigated: reaction time, temperature, amount of 2-methoxypropene, and amount of catalyst. The experiments showed that there is a neat balance between these parameters, leading to optimal reaction conditions at a reaction time of $200 \mathrm{~s}$ at $60{ }^{\circ} \mathrm{C}$ using $11 \mathrm{Eq}$ of 2-methoxypropene and $1 \mathrm{~mol} \%$ of CSA.

This set of optimal conditions was directly implemented in a 200 times larger reactor, leading to a good yield of the protected cyanohydrin product. In addition, we have shown that the chirality is retained during the reaction. It was also shown that the substrate scope under these conditions is somewhat restricted and that the reaction proceeds better in case electron-withdrawing substituents are present. The viability of the flow approach was further underlined by the successful MIP protection of a small series of cyanohydrin derivatives on a slightly larger scale.

\section{Experimental}

4.1. Continuous Flow System. A schematic representation of the microreactor setup is shown in Figure 1. All parts within the dotted line consist of a single glass microreactor with an internal volume of $92 \mu \mathrm{L}$, a channel width of $600 \mu \mathrm{m}$, a channel depth of $500 \mu \mathrm{m}$, and an effective channel length of $360 \mathrm{~mm}$. The channel layout contains two mixing units $\mathrm{M}$, being of the folding flow type. The reactor temperature was controlled by Peltier elements and sensed by a Pt1000 temperature sensor.

4.2. Reaction Optimization. A FutureChemistry FlowScreen (C-300) was used to perform the screening of reaction conditions. Four glass syringes with an internal volume of $5 \mathrm{~mL}$ were used in pumps P1, P2, P3, and P4 as indicated in Figure 1. 
Pump P1 contained solution of mandelonitrile (1, $590 \mu \mathrm{L}$, $5.0 \mathrm{mmol})$ and 2,6-dichlorotoluene $(130 \mu \mathrm{L}$, internal standard A) in $20 \mathrm{~mL}$ MTBE. Pump P2 contained a solution of camphorsulfonic acid $(46 \mathrm{mg}, 0.2 \mathrm{mmol})$ and $o$-xylene $(300 \mu \mathrm{L}$, internal standard B) in $20 \mathrm{~mL}$ MTBE. Pump P3 contained a solution 2-methoxypropene $(2,2.6 \mathrm{~mL}, 40.3 \mathrm{mmol})$ and nitrobenzene $(600 \mu \mathrm{L}$, internal standard $\mathrm{C})$. To quench the reaction at the end of the channel, ensuring well-defined residence times, pump P4 contained a solution of DIPEA $(840 \mu \mathrm{L}$, $4.8 \mathrm{mmol}$ ) in $19 \mathrm{~mL} \mathrm{MTBE}$, which was added to the reaction after the residence time channel (shown as meander channels in Figure 1). The product $(50 \mu \mathrm{L})$ was collected in $\mathrm{CH}_{2} \mathrm{Cl}_{2}(1 \mathrm{~mL})$ containing $0.15 \%$ o 4 -chloro-3-nitrotoluene as an external standard.

4.3. Scale-up Reaction. A scale-up experiment was performed in a Uniqsis FlowSyn (FCUQ-1020) equipped with a $20-\mathrm{mL}$ stainless steel coil reactor. With a flow of $2.0 \mathrm{~mL} / \mathrm{min}$ for A, B, and C, a residence time of $200 \mathrm{~s}$ was obtained. The product was collected for 14 min after 6 min of stabilization. Pump 1 continuously pumped a solution of mandelonitrile (1, $1.4 \mathrm{~mL}, 12 \mathrm{mmol}$ ) in $50 \mathrm{~mL}$ MTBE. Pump 2 was used for the solution containing camphorsulfonic acid $(139 \mathrm{mg}$, $0.6 \mathrm{mmol}$ ) in $200 \mathrm{~mL}$ MTBE. Pump 3 continuously pumped a solution of 2-methoxypropene $(2,44 \mathrm{~mL}, 0.7 \mathrm{~mol})$ in $165 \mathrm{~mL}$ MTBE. In contrast to the optimization setup, no quench pump was used because the residence time in the larger setup could easily be determined. In order neutralize the reaction, the product was collected in a solution of DIPEA $(1.5 \mathrm{~mL}, 8.5 \mathrm{mmol})$ in $28.5 \mathrm{~mL}$ MTBE. After collecting the product for $14 \mathrm{~min}$, the reaction mixture was washed with $50 \mathrm{~mL}$ demineralized water dried over $\mathrm{Na}_{2} \mathrm{SO}_{4}$, filtrated, and concentrated under reduced pressure to yield MIP-protected mandelonitrile (3, $1.2 \mathrm{~g}$, $5.8 \mathrm{mmol}, 94 \%$ pure) in $83 \%$.

4.4. Analysis. Off-line GC-MS analysis was performed with a Polaris Q GC-MS of ThermoFinnigan equipped with a VF1701MS column (length: $30 \mathrm{~m}$; internal diameter: $0.25 \mathrm{~mm}$; film thickness: $0.25 \mu \mathrm{m}$ ). An injector temperature of $250{ }^{\circ} \mathrm{C}$ was used. The initial column temperature was set to $80{ }^{\circ} \mathrm{C}$ increasing to $150{ }^{\circ} \mathrm{C}$ using $20{ }^{\circ} \mathrm{C} / \mathrm{min}$ ramp, directly followed by a ramp of $40{ }^{\circ} \mathrm{C} / \mathrm{min}$ to a temperature of $280^{\circ} \mathrm{C}$ which was maintained for $2.25 \mathrm{~min}$. The total GC program took $10 \mathrm{~min}$. Mass spectrometry was performed in electron ionization mode. A 2-min delay was set in the detection to cut-off the solvent peak. A spit flow of 50 was used, and the samples were analyzed in a mass range from $20-650$. The product sample obtained from the microreactor was collected in dichloromethane containing $0.15 \%$ \% 4 -choloro-3-nitrotoluene as an external standard. Accurate flow rates were calculated using our recently developed flow marker methodology [9].

Acknowledgments. The authors thank Pieter Nieuwland (FutureChemistry, Nijmegen, NL) for support and fruitful discussions. The NWO-ACTS Process-on-a-Chip (PoaC) program is kindly acknowledged for financial support.

\section{Supporting information available}

Supplementary data (of compounds 8-11) associated with this article can be found in the online version at www.akademiai.com

\section{References and Notes}

1. (a) Peterson, C. J.; Tsao, R.; Coast, J. R. Pest. Manage Sci. 2000, 56, 615-617; (b) Khan, N. H.; Kureshy, R. I.; Abdi, S. H. R.; Agrawal, S.; Jasra, R. V. Coord. Chem. Rev. 2008, 252, 593-623.

2. Poulton, J. E. Plant Physiol. 1990, 94, 401-405.

3. Lapworth, A. J. Chem Soc. 1903, 83, 995-1005.

4. Rosenthaler, L. Biochem. Z. 1908, 14, 238-253.

5. (a) Gregory, R. J. H. Chem. Rev. 1999, 99, 3649-3682; (b) Holt, J.; Hanefelt, U. Curr. Org. Synth. 2009, 6, 15-37; (c) Wang, W.; Liu, X.; Lin, L.; Feng, X. Eur. J. Org. Chem. 2010, 4751-4769; (d) Baeza, A.; Sansano, J. M.; Saá, J. M.; Nájera, C. Pure App. Chem. 2007, 79, 213-221; (e) North, M. Tetrahedron: Asymmetry 2003, 14, 147-176; (f) Purkarthofer, T.; Skranc, W.; Schuster, C.; Griengl, H. Appl. Microbiol. Biotechnol. 2007, 76, 309-320; (g) Ritzen, B.; Hoekman, S.; Durán Verdasco, E.; van Delft, F. L.; Rutjes, F. P. J. T. J, Org. Chem. 2010, 75, 3461-3464.

6. (a) Koch, K.; van den Berg, R. J. F.; Nieuwland, P. J.; Wijtmans, R.; Schoemaker, H. E.; van Hest, J. C. M.; Rutjes, F. P. J. T. Biotechnol. Bioeng. 2008, 99, 1028-1033; (b) Koch. K.; van den Berg, R. J. F.; Nieuwland, P. J.; Wijtmans, R.; Wubbolts, M. G.; Schoemaker, H. E.; Rutjes, F. P. J. T.; van Hest, J. C. M. Chem. Eng. J. 2008, 135 S, S89-S92.

7. For an extensive research on catalytic THP- and MIP-alcohol protections, see: Kotke, M.; Schreiner, P. R. Synthesis, 2007, 5, 779-790.

8. (a) Delville, M. M. E.; Nieuwland, P. J.; Janssen, P.; Koch, K.; van Hest, J. C. M.; Rutjes F. P. J. T. Chem. Eng. J. 2011, 167, 556-559; (b) van den Broek, S. A. M. W.; Leliveld, J. R.; Becker, R.; Delville, M. M. E.; Nieuwland, P. J.; Kock. K.; Rutjes, F. P. J. T. Org. Process Res. Dev. 2012, 16, 934-938; (c) van den Broek, S. A. M. W.; Becker, R.; Kössl, F.; Delville, M. M. E.; Nieuwland, P. J.; Kock. K.; Rutjes, F. P. J. T. ChemSusChem 2012, 5, 289-292.

9. (a) Zandbergen, P.; van den Nieuwendijk, A. M. C. H.; Brussee, J.; van der Gen, A. Tetrahedron 1992, 48, 3977-3982; (b) Lu, W.; Chen. P.; Lin, G. Tetrahedron 2008, 64, 7822-7827.

10. Nieuwland, P. J.; Koch, K.; van Harskamp, N.; Wehrens, R.; van Hest, J. C. M.; Rutjes, F. P. J. T. Chem. Asian J. 2010, 5, 799-805.

11. Nieuwland, P. J.; Koch, K.; Rutjes, F. P. J. T.; van Hest, J. C. M. Open Chem. Eng. J. 2010, 4, 61-67.

12. MacInnes, J. M.; Vikhansky, A.; Allen, R. W. K. Chem. Eng. Sci. 2007, $62,2718-2727$.

13. This software is commercially available: www.futurechemistry.com.

14. $(R)$-Mandelonitrile $(90 \%$ ee) was purchased from Sigma-Aldrich and used without further purification. 